BIODIVERSITY AND ECOLOGY

\section{Sounds in the key of life}

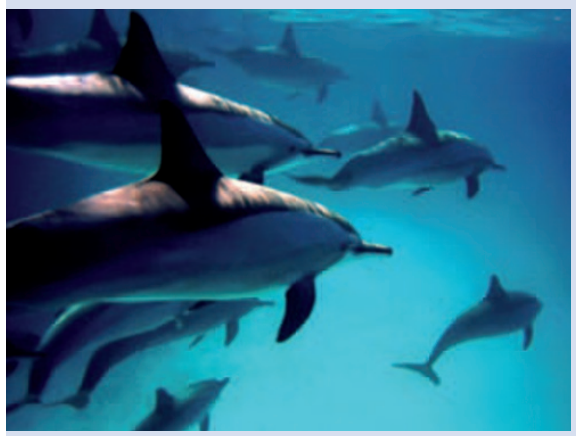

Geophys. Res. Lett. 35, L19601 (2008)

The oceans could get noisier as an unexpected consequence of climate change, suggests new research. The continued use of fossil fuels is expected to make the ocean both more acidic and warmer, with the knock-on effect that it will transmit low- to mid-frequency sounds over longer distances.

It has long been known that acidity affects how sound travels in seawater, but until now the impact of climate change on ocean acoustics has been overlooked.
Scientists led by Peter Brewer at

Monterey Bay Aquarium Research Institute in Moss Landing, California, calculated that if ocean acidity drops $0.3 \mathrm{pH}$ units by 2050 , as projected by some studies, the absorption of sound waves at 1 kilohertz and below will decline by 40 per cent. Using previous experimental and field data, Brewer and colleagues also found that between the late nineteenth century and early 1990s, absorption decreased by up to 15 per cent in response to changes in ocean chemistry. This effect occurs largely as a result of $\mathrm{pH}$-sensitive changes in the balance of borate compounds, which are tuned to absorb energy from sound waves of 1 kilohertz and below in seawater.

Ambient ocean noises in the auditory range for marine mammal communication and military activity are set to increase as a result of decreased sound absorption and could travel up to 70 per cent farther underwater by 2050 , say the scientists.

\section{Olive Heffernan}

\section{ATMOSPHERIC SCIENCE}

\section{Physical effects}

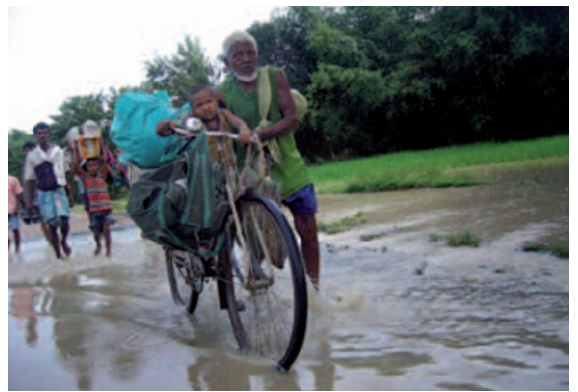

J. Climate 21, 4647-4663 (2008)

Establishing a physical link between warming in the tropical Pacific and the regional climate of Bangladesh could allow researchers to predict how climate change will influence future outbreaks of cholera there.

Now scientists say that increased rainfall, rather than temperature, may be the main factor that causes a surge in the water-borne disease in El Niño years in Bangladesh. El Niño-Southern Oscillation events - anomalous rises in tropical Pacific sea surface temperatures associated with shifts in atmospheric circulation that occur every three to seven years - have previously been linked to cholera outbreaks in Bangladesh, but until now a physical explanation for this relationship has been lacking.
Benjamin Cash of the Center for Ocean-Land-Atmosphere Studies, Maryland, and colleagues used a global circulation model to investigate the effects of El Niñoinduced warming in the tropical Pacific on the climate of Bangladesh. Simulated increases in sea surface temperature altered wind patterns to the west of Bangladesh, leading to an accumulation of moisture in the region and greater rainfall during the summer monsoon season. The researchers suggest that this increase in rainfall, which exacerbates the risk of flooding and thus disease proliferation, is the cause of the more frequent outbreaks of cholera in El Niño years.

Anna Armstrong

CLIMATE IMPACTS

Minor disturbances

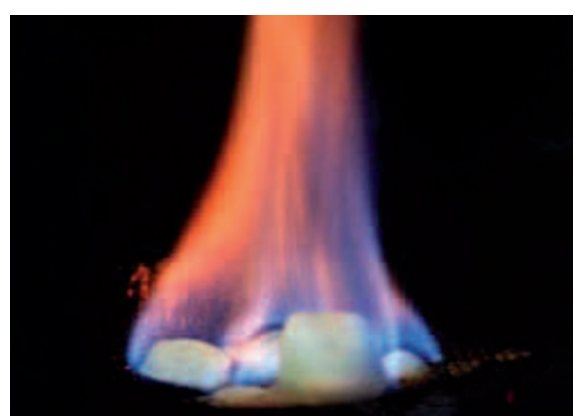

Geophys. Res. Lett. 35, L19806 (2008)

Methane deposits stored beneath the sea floor are unlikely to be a major contributor to climate change in the coming century, suggests a new study. Methane clathrates, ice-like structures of water and the potent greenhouse gas methane, are thought to be easily destabilized by rising ocean temperatures.

Jean-François Lamarque of the National Center for Atmospheric Research, Colorado, used climate model simulations to estimate the amount of methane from deep hydrates that could be released in high carbon dioxide conditions. He found that if atmospheric carbon dioxide emissions increase by 1 per cent a year over the coming century, up to 2,140 million tonnes of methane could enter the ocean. But recent observational data indicate that only 5 to 21 million tonnes of methane would then be released to the atmosphere, much less than the 500 million tonnes of methane presently emitted each year. However, much of the gas that doesn't initially reach the atmosphere could be utilized by marine microbes, resulting in a secondary release of carbon dioxide to the atmosphere.

The greatest amount of destabilization is expected to occur north of the Arctic Circle. The author notes that shallow methane clathrates may remain intact as rising sea levels could stabilize the deposits.

\section{Alicia Newton}

CLIMATE PREDICTION

\section{Foreboding forecast}

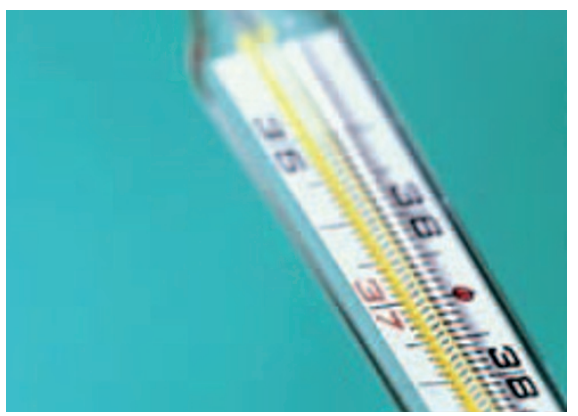

Proc. NatlAcad. Sci. USA 105, 15258-15262 (2008)

Even the most stringent of proposed climate mitigation measures may not avert dangerous climate change, shows a new analysis. An increase in global average surface temperature of ${ }^{\circ} \mathrm{C}$ above pre-industrial values is generally considered to be the level of warming that could have serious impacts and, as such, is to be avoided.

Detlef van Vuuren of the Netherlands Environment Assessment Agency and colleagues assessed the possible impacts of various climate policies published in the 
literature on twenty-first century warming using two reduced-complexity climate models and recently developed multigas mitigation scenarios. For policies that aim to stabilize atmospheric greenhouse gas concentrations at the lowest levels being proposed, there was an average warming of $1.9^{\circ} \mathrm{C}$, with a full range of $1.1-3.4^{\circ} \mathrm{C}$, above pre-industrial temperatures by 2100 . They found that in the absence of climate policy, temperatures could increase $2.0-8.3^{\circ} \mathrm{C}$ above pre-industrial values by the end of the century.

The authors stress that the most ambitious policies optimistically assume the global deployment of new technologies and policies over relatively short periods of time, yet still lead to considerable increases in global mean temperature. They warn that adaptation will be needed alongside mitigation to reduce the impacts of future warming.

Olive Heffernan

ATMOSPHERIC SCIENCE

\section{Riddle resolved}

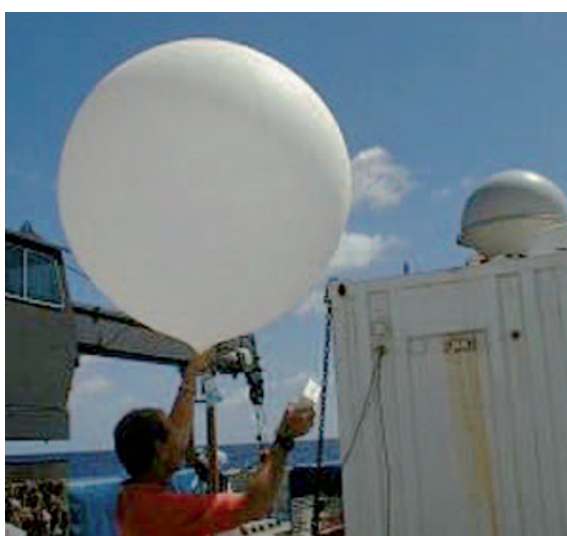

Int. J. Climatol. doi:10.1002/joc.1756 (2008)

Until recently, data from satellites and weather balloons have shown less warming in the tropical lower atmosphere than on the land and ocean surface, a result inconsistent with model simulations and basic theory, and also at odds with the massive body of evidence on human-induced climate change. But this enduring conundrum in climate science has now been resolved.

A large consortium of scientists led by Benjamin Santer of the Lawrence Livermore National Laboratory in California set out to test a claim by David Douglass of the University of Rochester, New York, and colleagues that 'models and observations disagree to a statistically significant extent' on the issue of tropical warming. Bringing a variety of independent observational data sets and state-of-the-art climate models to the task, they found that the earlier study, also published in the International
Journal of Climatology, reached an incorrect conclusion owing to the use of a flawed statistical test and older observational data.

Santer and colleagues were able to reconcile temperature trends in the models with observations by using more appropriate statistical tests, new satellite and weather-balloon data that show greater warming of the tropical lower atmosphere, and improved satellite and buoy data that yielded slightly lower estimates of surface warming.

\section{Olive Heffernan}

\section{BIODIVERSITY AND ECOLOGY}

\section{Taxing the tropics}

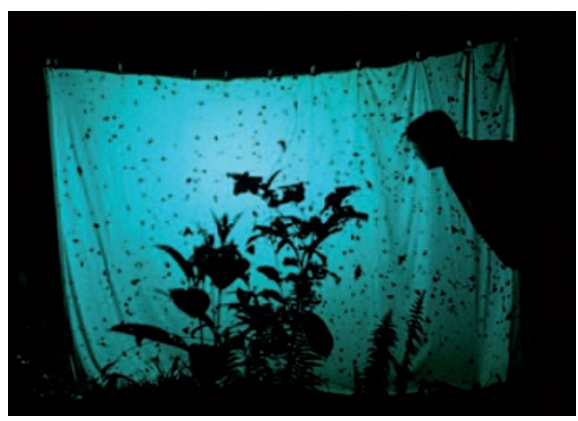

Science 322, 258-261 (2008)

Lowland tropics could lose a substantial proportion of their plant and insect biodiversity by 2100 , according to a new study. The tropics are predicted to warm by about $3{ }^{\circ} \mathrm{C}$ by the end of this century, which would shift current temperature zones 600 metres uphill. Until now, little attention has been paid to the impact of this shift on tropical inhabitants.

Ecologist Robert Colwell of the University of Connecticut and colleagues scaled a Costa Rican volcano, rising 2,900 metres above sea level, to determine the elevation ranges of 1,902 plant and insect species. Applying a simple model to their data, they conjecture that a regional temperature rise of $3.2^{\circ} \mathrm{C}$ would shift many lowland occupants upward into completely new territory, possibly leaving low-lying rainforest bereft of many current inhabitants. With few replacements adapted to higher temperatures waiting in the wings, species richness in the region may be set to fall. At the same time, species living near the tip of the mountain will experience a contraction in their elevation range, increasing the risk of extinctions.

Although more research is needed to determine the tolerance of lowland species to temperature gains, it is clear that climate change poses a substantial threat to tropical biodiversity.

Anna Armstrong

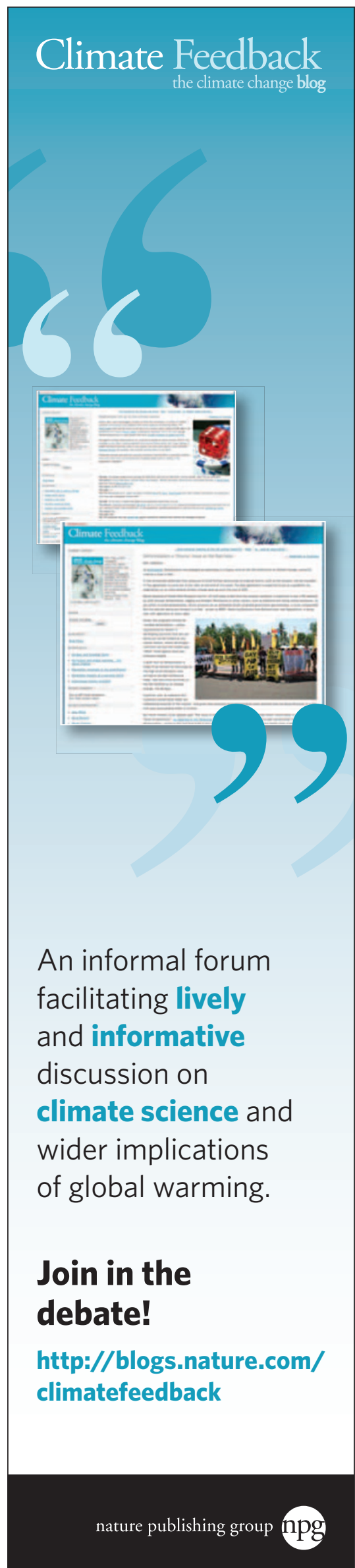

